http://jmscr.igmpublication.org/home/

ISSN (e)-2347-176x ISSN (p) 2455-0450

crossref DOI: https://dx.doi.org/10.18535/jmscr/v7i12.43

Journal Of Medical Science And Clinical Research

\title{
Effect of Community Based Rehabilitation on the Quality of Life of People with Locomotor Disabilities in Vadakkupalayam Village of Cuddalore District
}

\author{
Authors \\ Balamurugan $\mathbf{R}^{1}$, Dhanpal Singh ${ }^{2}$, Mohandas Kurup ${ }^{3}$ \\ Department of Physical Medicine and Rehabilitation, Rajah Muthiah Medical College and Hospital, \\ Annamalai Nagar, Chidambaram, Tamilnadu
}

\begin{abstract}
Introduction: It is estimated that around 20\% of total disabled population is locomotor disabled, out of which 57\% are from rural areas. These disabilities affect their quality of life. Rehabilitation measures extended to these affected population aims at improving their quality of life and economic independence. These interventions provided at the community level rather than to individual persons, have a better outcome. Expanding Community Based Rehabilitation (CBR) is the need of hour. In India, there are very few studies on CBR and Quality of Life (QOL) of locomotor disability. Our study was intended as a pilot study for CBR. This study aims to find out the effect of Community Based Rehabilitation (CBR) on the quality of life of people with locomotor disabilities in Vadakkupalayam village of Cuddalore district in Tamilnadu as it can give us a sample picture for implementation of future CBR programmes.

Aim: 1. To find out the prevalence of locomotor disability in Vadakkupalayam village of Cuddalore district. 2. To find out the effectiveness of Community Based Rehabilitation (CBR) on the Quality of Life (QOL) of people with locomotor disabilities in the area.
\end{abstract}

Materials and Methods: This study was conducted as Quasi Experimental Study. Secondary data was collected and survey with questionnarie was done to identify people with locomotor disabilities (52) after which rehab interventions were given. WHODAS 2.0 scale was used before and after rehab intervention and t-test was used for statistical analysis and the data was obtained.

Results: As mean WHODAS decreases, the quality of life of person with locomotor disability increases. Comparison of pre- and post- intervention WHODAS showed that there was a statistically significant difference observed $t=15.084, p<0.001$. It can be inferred that CBR has improved the quality of life of person affected with locomotor disability among the selected participants in this study.

Conclusion: Our study shows that Community based Rehabilitation has improved the quality of life of person affected with locomotor disability among the study population. Awareness to the public through information booklets and mobile therapy vans will enable the people, especially in rural areas, to benefit from the rehabilitative measures provided by the government and non-governmental organisations.

Keywords: Locomotor disability, Community based rehabilitation, Quality of life.

\section{Introduction}

In India, out of the 121 Crore $(\mathrm{Cr})$ population, $2.68 \mathrm{Cr}$ persons are 'disabled' which is $2.21 \%$ of the total population. According to census of
$2011^{1}, 20 \%$ out of total disabled population is locomotor disabled. Among the male disabled, $22 \%$ are having disability in movement. In the case of the female disabled, $18 \%$ has disability in 
movement and $8 \%$ of them are having multiple disabilities. Among the disabled non-workers with disability in movement, $49.8 \%$ are dependents and $19.7 \%$ are students ${ }^{2}$.

Locomotor disability includes a person with loss or lack of normal ability to execute distinctive activities associated with the movement of self and objects from place to place. In general, the conditions may include paralysis of limb or body, deformity of limb, maximum loss of limb, dysfunction of limb, deformity of joints of limb, deformity of the body other than limbs.

It may be due to congenital and developmental causes like Cerebral Palsy (CP), Congenital Talipes Equinovarus (CTEV), meningocele, phocomelias, congenital dislocation of hip, etc.

Acquired causes can be infections like tuberculosis of spine or other joints, chronic osteomyelitis, septic arthritis, acute poliomyelitis, Guillian Barre syndrome, leprosy, encephalitis, AIDS etc.

Traumatic causes are traffic accidents, domestic accidents, industrial accidents, agricultural accidents, fall from height, bullet injuries, explosions, violence, sports injuries, injuries from natural calamities.

Vascular causes are cereberovascular disease, peripheral vascular disease, Perthe's disease. Neoplastic conditions of brain like astrocytoma, meningioma, spinal tumors, osteosarcoma etc, can be the cause of the disability. Metabolic causes include rickets, diabetic neuropathy, vit.B12 deficiency, gout. Degenerative causes include motor neuron disease, Parkinson's disease, multiple sclerosis, osteoarthritis, spondylosis. Other causes include Muscular dystrophies, Lathyrism, Rheumatoid Arthritis.

Community based rehabilitation $(\mathrm{CBR})^{3}$ is " $\mathrm{A}$ strategy within community development for the rehabilitation, equalization of opportunities and social intergration of all people with Disabilities". Principles of CBR are Equality, Social justice, Solidarity, Intergration \& Dignity.

The development and execution of CBR programs is guided by the WHO CBR Matrix ${ }^{4}$, which consists of five key components- health, education, livelihood, social and empowerment components. This study particularly concentrates on the health component.

World Health Organisation (WHO) defines Quality of Life ${ }^{5}$ as an individual's perception of their position in life in the context of the culture and value systems in which they live and in relation to their goals, expectations, standards and concerns. It is a broad-ranging concept affected in a complex way by the person's physical health, psychological state, personal beliefs, social relationships and their relationship to salient features of their environment. All these are significantly affected by persons ability to move.

There have been many studies in community based rehabilitation in general but studies on the effectiveness of CBR in locomotor disability particularly in increasing the quality of life is much needed one. As locomotor disability due to trauma is on the rise this study will help in designing the rehabilitation approach and to provide better quality of life to the affected population.

This study was conducted in Vadukkapalayam village of Cuddalore district in Tamilnadu. This study was done through regular outreach camps by the department of Physical Medicine \& Rehabiltation (PMR), Rajah muthiah medical college with the help of Leprosy mission trust India (TMLTI) Which has been doing CBR works in Cuddalore and throughout India. WHODAS $2.0^{7}$ scale, used in our study, is a generic instrument developed by WHO to provide a standardized method for measuring health and disability across cultures and simple to administer. Assessing on person's ability to move in a way reflects quality of life of the person which is the motto of this study.

\section{Aims and Objectives}

1. To find out the prevalence of locomotor disability in Vadakkupalayam village of Cuddalore District, Tamilnadu. 
2. To find out the effectiveness of Community Based Rehabilitation (CBR) on the Quality Of Life (QOL) of people with locomotor disabilities in the area

\section{Materials and Methods}

This Quasi-Experimental study was conducted in Vadakkupalayam village of Cuddalore district of Tamilnadu in three phases, from September 2017 to October 2018. Selection criteria included subjects affected by locomotor impairment due to any cause and falling under the age group of 17 years to 60 years. Informed consent was obtained from every participant.

Secondary data was collected and survey was done to find out people affected by locomotor disability. 52 people were identified with locomotor disability and was provided with questionnaire after brief explanation about the study and the questionnaire. All the 52 completed questionnaires were taken for data analysis. Number of days the patients' ability to work was affected was also obtained. WHODAS 2.0 scores were calculated summing the scores.

In phase 2, awareness was created about latest disability act and benefits given by government by distribution of Information booklet. They were given exercises for mobility, occupational therapy to improve Activities of Daily Living (ADL) functions, given orthotic devices. They were also given instructions to carry out home based training activities. Those who required tertiary care were evaluated and referred to higher centres. Outreach camps were conducted using therapy van for assessment provided with physical modalities was used for those with pain.

In phase 3 , the study population was assessed by interviewer according to the WHODAS 2.0 questionnaire after the rehabilitation interventions. The data obtained were statistically analysed using t-test.

\section{Statistical Analysis}

Comparison of pre- and post- intervention WHODAS scores showed that there was a statistically significant difference observed $\mathrm{t}=15.084, \mathrm{p}<0.001$ Comparison of pre- and postintervention WHODAS among male showed that there was a statistically significant difference observed $\mathrm{t}=12.471, \mathrm{p}<0.001$ while pre- and postintervention days affected among male showed that there was a statistically significant difference observed $\mathrm{t}=7.005, \mathrm{p}<0.001$

Comparison of pre- and post- intervention WHODAS among female showed that there was a statistically significant difference observed $\mathrm{t}=8.243, \mathrm{p}<0.001$. While pre- and postintervention days affected among female showed that there was a statistically significant difference observed $\mathrm{t}=7.415, \mathrm{p}<0.001$.

\section{Results}

Total no. of locomotor disabled people identified were 52 out of 152 disabled accounting for $34 \%$. Among them, gender variation was 59.6\% male and $40.4 \%$ female. Age group of participants diagnosed with locomotor disability constituted $26.9 \%$ (21-30 years), 25\% (31-40), 21.2\%, (4150) more than 50 yrs-17.3\%. In this study degenerative causes were the reason behind $51.92 \%$ of locomotor disablility, Next to it stand vascular causes (13.46\%) and Acquired cases infective (11.53\%). Comparison between pre and after intervention showed that as mean WHODAS2.0 decreases the quality of life of person with locomotor disability increases. Number of work affected days decreased after rehab intervention.

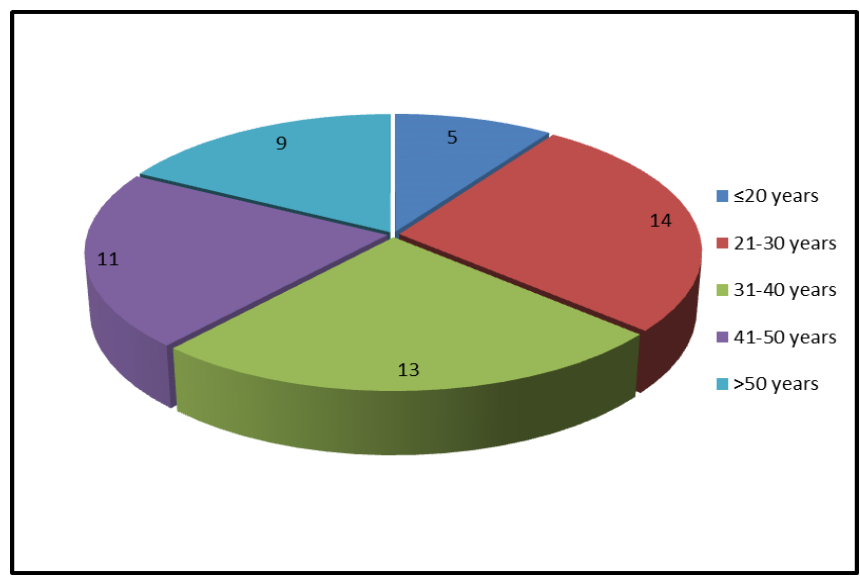

Figure 1 Age distribution of study participants diagnosed with Locomotor Disability 


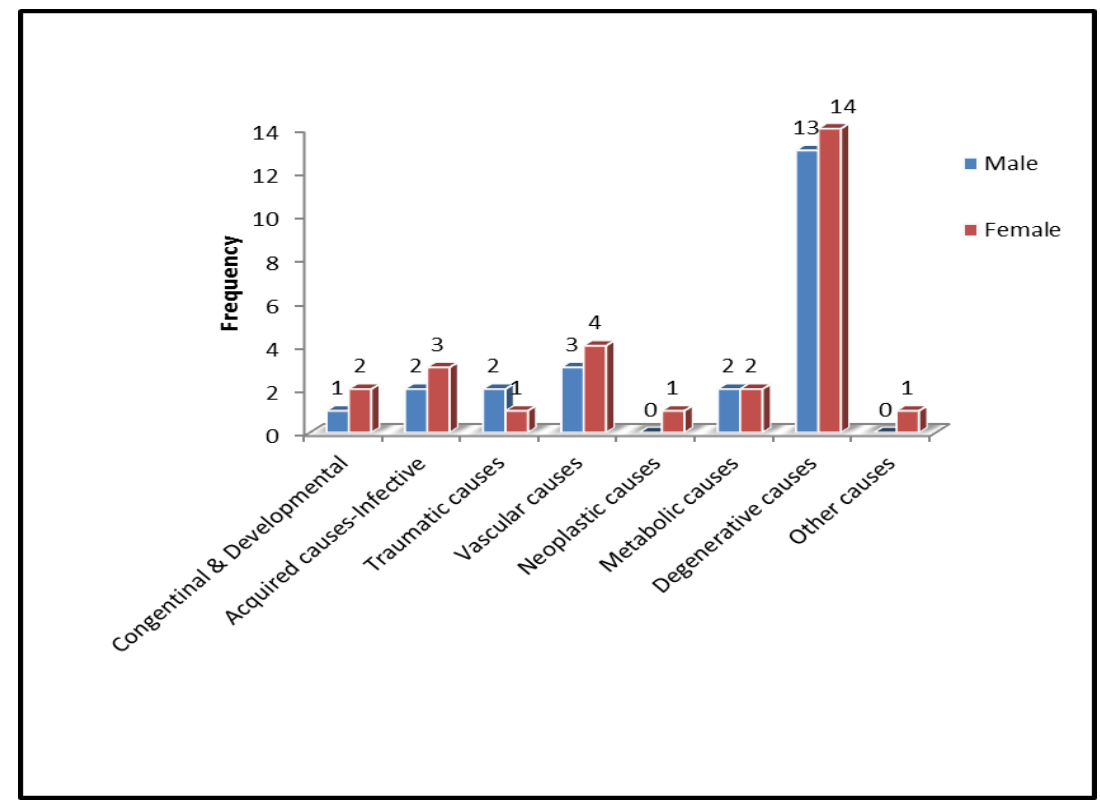

Figure 2: Distribution of different causes of Locomotor Disability between male and female

Table 1: Comparison of Pre and Post Intervention Whodas Scores

\begin{tabular}{|c|c|c|c|c|c|}
\hline Parameters & $\mathbf{N}$ & Mean & S.D & Paired $t$ value & p value \\
\hline $\begin{array}{l}\text { WHODAS } \\
\text { Pre-intervention }\end{array}$ & 52 & 19.09 & 4.2021 & \multirow[b]{2}{*}{15.084} & \multirow[b]{2}{*}{$0.000 *$} \\
\hline $\begin{array}{l}\text { WHODAS } \\
\text { post- intervention }\end{array}$ & 52 & 15.37 & 4.352 & & \\
\hline $\begin{array}{l}\text { Days affected } \\
\text { Pre-intervention }\end{array}$ & 52 & 14.87 & 5.807 & \multirow[b]{2}{*}{9.988} & \multirow[b]{2}{*}{$0.000 * *$} \\
\hline $\begin{array}{l}\text { Days affected post- } \\
\text { intervention }\end{array}$ & 52 & 12.13 & 4.923 & & \\
\hline
\end{tabular}

Significant $\mathrm{p}-<0.001$

Table 2: Comparison of pre- and post- intervention WHODAS-gender variation

\begin{tabular}{|c|c|c|c|c|c|c|}
\hline Sex & Parameters & $\mathbf{N}$ & Mean & S.D & paired t- test & p value \\
\hline \multirow{4}{*}{ Male } & $\begin{array}{l}\text { WHODAS } \\
\text { pre-intervention }\end{array}$ & 31 & 19.258 & 4.041 & \multirow{2}{*}{12.471} & \multirow{2}{*}{$0.000^{* *}$} \\
\hline & $\begin{array}{c}\text { WHODAS } \\
\text { post- intervention }\end{array}$ & 31 & 15.45 & 4.154 & & \\
\hline & $\begin{array}{c}\text { Days affected } \\
\text { pre-intervention }\end{array}$ & 31 & 15.23 & 5.696 & \multirow{2}{*}{7.005} & \multirow{2}{*}{$0.000^{* *}$} \\
\hline & $\begin{array}{c}\text { Days affected } \\
\text { post-intervention }\end{array}$ & 31 & 12.61 & 4.602 & & \\
\hline \multirow{3}{*}{ Female } & $\begin{array}{c}\text { WHODAS } \\
\text { pre-intervention }\end{array}$ & 21 & 18.857 & 4.5198 & \multirow{2}{*}{8.243} & \multirow{2}{*}{$0.000^{* *}$} \\
\hline & $\begin{array}{c}\text { WHODAS } \\
\text { post- intervention }\end{array}$ & 21 & 15.24 & 4.732 & & \\
\hline & Days affected & 21 & 14.33 & 6.069 & 7.415 & $0.000^{* *}$ \\
\hline
\end{tabular}


Table 3 Comparison of pre- and post- intervention WHODAS-Age variation

\begin{tabular}{|c|c|c|c|c|}
\hline Age & Parameters & $\mathbf{N}$ & Mean & S.D \\
\hline \multirow{4}{*}{1} & WHODAS & 3 & 20.000 & 0.000 \\
\hline & WHODAS after intervention & 3 & 17.000 & 1.732 \\
\hline & Days affected & 3 & 17.33 & 2.082 \\
\hline & Days affected after intervention & 3 & 14.33 & 2.082 \\
\hline \multirow{4}{*}{2} & WHODAS & 16 & 19.00 & 4.457 \\
\hline & WHODAS after intervention & 16 & 15.69 & 4.644 \\
\hline & Days affected & 16 & 12.56 & 6.282 \\
\hline & Days affected after intervention & 16 & 10.19 & 4.875 \\
\hline \multirow{4}{*}{3} & WHODAS & 18 & 19.333 & 4.652 \\
\hline & WHODAS after intervention & 18 & 15.61 & 4.565 \\
\hline & Days affected & 18 & 15.67 & 5.087 \\
\hline & Days affected after intervention & 18 & 12.89 & 4.676 \\
\hline \multirow{4}{*}{4} & WHODAS & 11 & 18.091 & 3.780 \\
\hline & WHODAS after intervention & 11 & 14.18 & 3.945 \\
\hline & Days affected & 11 & 15.82 & 6.897 \\
\hline & Days affected after intervention & 11 & 12.82 & 5.546 \\
\hline \multirow{4}{*}{5} & WHODAS & 4 & 20.55 & 4.795 \\
\hline & WHODAS after intervention & 4 & 15.00 & 5.774 \\
\hline & Days affected & 4 & 16.00 & 4.967 \\
\hline & Days affected after intervention & 4 & 13.00 & 5.715 \\
\hline \multirow[b]{3}{*}{ Total } & WHODAS & 52 & 19.096 & 4.202 \\
\hline & WHODAS after intervention & 52 & 15.37 & 4.352 \\
\hline & Days affected & 52 & 14.87 & 5.807 \\
\hline
\end{tabular}

\section{Discussion}

Early identification and treatment can reduce the severity of locomotor disability. People in rural areas and low socio economic status are deprived of these rehabilitation interventions due to lack of awareness and financial constraints. Regular outreach camp serves as a valuable tool in identifying weakness at an early stage so that corrective measures can be taken up to prevent worsening of the condition. In this study, we have taken Vadakkupalayam village in Cuddalore district of Tamilnadu as a model village for Community Based Rehabilitation.

Our study proves that many people with locomotor disability in rural areas remain unidentified and they can benefit from CBR program. A study by Amaritchavaran et $\mathrm{al}^{8}$ reveals that there are many persons with untreated disabling conditions in rural communities, and that a significant number of them can benefit from medical treatment and rehabilitation.in our study, we were able to identify 52 people with locomotor disabilities among a population of 4961 and 8 of them were without any history of previous treatment and referred to higher centres after counselling.

Sustainability of the program is another important requirement which determines the success of program. Jay kumar et $\mathrm{al}^{9}$ in their study showed the sustainability of interventions through activities involving the community structures. In our study, we were able to identify people with locomotor disabilities and train them to develop in-house orthotic devices using the resources available to them. We also taught them homebased self training exercises. The importance of establishing and promoting community structures to support CBR sustainability is necessary for success of any CBR program. CBR initiative appears to be most beneficial to those who have mild physical disability.

In our study, among the causes of locomotor disability, trauma is attributed as the reason to locomotor disabilities of most severe nature. 3 out of 52, were severely affected on several parameters of quality of life. Similiar findings were obtained by Sandip Dhole etal ${ }^{10}$ with traumatic locomotor permanent disability constituting $14.97 \%$. 
Our study revealed that older age and stroke (9.6\%) resulted in increased functional dependency. Similar results were obtained by susanraju $^{11}$ which concluded that presence of anxiety, depression and functional dependence were associated with impaired QoL.

The prevalence of locomotor disability was more among males (59.6\%) than females (40.4\%).

The information collected shows that such programmes were effective in that they increased independence and improved mobility and communication skills of disabled persons. As age increases, there was a positive association with disability. Quality of life and disability limitation are affected by the availability and utility of rehabilitative services. Low literacy levels and poor awareness of rehabilitation facilities were the major factors affecting treatment seeking pattern of individuals with locomotor disability. Similiar results were obtained by santoshihalder ${ }^{12}$.

Comparison of pre and after intervention days affected showed that there was a statistically significant difference observed $t=9.988, p<0.001$.

It can be inferred that Community based Rehabilitation has improved the quality of life of person affected with locomotor disability among the selected participants in this study. The mean of the days that the patient can move has increased as the result of CBR. CBR can have a positive impact on people with disabilities. Similar results were obtained by sunil Deepak ${ }^{13}$ et al.

\section{Conclusion}

Our study shows that community based rehabilitation can improve the lives of locomotor disabled people and also in identifying the needy ones for active intervention at rehab level who can be referred to higher centres for further management. Therapy vans as part of community based rehabilitation can have a far reaching implication if carried out in rural areas.

\section{Limitation of Study}

Limitation of the present study is duration of community based rehabilitation and limited resources.

\section{References}

1. Census 2011-census of in2011 http://censusindia.gov.in/

2. Disabled persons in a statistical profile 2016 (http://mospi. nic.in/sites/ default/files/publication_reports/Disabled persons in India 2016.pdf)

3. A concise textbook of CBR:satya bhusan Nagar

4. WHO CBR MATRIX-https://www. who.int/disabilities/cbr/guidelines/en/

5. Development of the World Health Organization WHOQOL-BREF quality of life assessment. The WHOQOL Group. Psychol Med. 1998 May; 28(3):551-8.

6. LEPROSY MISSION TRUST OF INDIAhttps://www.leprosymission.in/

7. WHODAS 2.0

https://www.who.int/classifications/icf/wh odasii/en/

8. Prevalence of disabling conditions in a rural northern Thai community: a survey conducted by village health communicators. Swaddiwudhipong W1, Amaritchavarn V, Boonyabuncha S. Disabil Rehabil. 1993 Apr-Jun; 15(2):839.

9. Sustainability: lessons from a communitybased rehabilitation programme in Karnataka, India Fairlene Soji, Jay Kumar and Sara Varughese Knowledge Management for Development Journal

10. Sandip Dhole, Anil Kumar S. N. More, Harshanand J Popalwar, Vaibhav Lokhande Study of Locomotor Disability Due To Various Types Of Trauma Gaur NjmrVolume 5Issue

11. J Psychosocial Problems, Quality of Life, and Functional Independence Among Indian Stroke Survivors Rinu Susan Raju, 
MA, MPhil; Prabhakaran S. Sarma, PhD; Jeyaraj D. Pandian, MD, DM

12. JAASEP WINTER, 2013 Nature and Causes of Locomotor Disabilities in India Santoshi Halder, M.A., Ph.D. Fulbright Nehru Senior Research Fellow (20112012) School of Education, Indiana University Assistant Professor, Department Of Education, University of Calcutta, Alipore Campus, Arindam Talukdar, M.Pharm, Ph.D. Senior Research Scientist, Pharmacy, Albany Molecular, Singapore July - Sept 2015.

13. Disability, CBR \& Inclusive Development, Vol 24, No 4 (2013) Impact of Community-based Rehabilitation on Persons with Different Disabilities. Sunil Deepak, Mario Biggeri, Vincenzo Mauro, Jayanth Kumar, Giampiero Griffo. 